$\frac{\text { JER }}{\text { KUSOED }}$

Journal of Education and Research

August 2013, Vol. 3, No. 2, pp. 1-14

DOI: http://dx.doi.org/10.3126/jer.v3i2.8191

\title{
Educational Thinking from the Perspective of Children: Contemporary Comments on a Traditional Slogan
}

\author{
Stefan Gross* and Ulrich Wehner \\ Institute of Early Childhood Education, University of Education, Karlsruhe, Germany
}

\begin{abstract}
Educational thinking has always been linked with a specific view on children.

Although it is a matter of common knowledge, in closer examination the authors figure out that educational concepts deal surprisingly and imprecisely with their keysubject. While progressive approaches made the term "From the perspective of the child” famous some 100 years ago, a brief analysis and the post-history enlightened contradictions, misunderstandings, and, in parts, fatal consequences of a careless or dogmatic use of the slogan. In their inconvenient meta-analysis, the authors vote for a consequent re-interpretation of the ideologically overloaded slogan by using it as a critical working-formula. Doing this, educational thinking from the perspective of children has massive consequences on the practical interaction between adults and children and the theoretical foundations of pedagogy. And it opens the door for a different kind of educational research with its objective to analyze the variety, heterogeneity and diversity of the life-world of children.
\end{abstract}

Keywords: Progressive education, child-focused education, Maria Montessori, intergenerational relationship, Bildung and self-cultivation, educational interaction

Educational thinking from the perspective of children - this sounds, at first sight, like a natural matter, of course, without further need for theoretical reflection or explanation. Without any deeper study or knowledge of educational history, it seems as evident as the request "to start reading at the beginning of a sentence" or "to start jumping from the ground" - what else?

In contrast to this educational common sense understanding of today's general public, the scientific community of educational specialists - equipped with their distinct theories and with a long history full of controversial pedagogical ideas - associates this slogan mainly ISSN: 2091-0118(Print)/2091-2560(Online) Email: st_gross@gmx.net 
with the so called "progressive" or "alternative" approaches. Historically, their origins are located in the transition period from the 19th to the 20thcentury in Europe and America ${ }^{1}$ consolidating a growing variety of different movements, combined by their mutual objective to renew education, teaching and schools starting from the very bottom. The names of the protagonists of those days even sound today like who-is-who in the field of education and cannot be missed in any classical collection of great educational thinkers. Maria Montessori (1870-1952), Rudolf Steiner (1861-1925), Ellen Key (1849-1926) and John Dewey (18591952) are some of the most discussed personalities in the academia. Although their perspectives vary theoretically in many aspects, their common base is starting educational thinking "from the child", illustrating and emphasizing the important role children should play in any pedagogical thought. While advocates and supporters of progressive approaches highlight the liberation of the child in these concepts, critics assert an excessive demand and imposition putting the whole weight of educational responsibility on just too small shoulders. Still today, the slogan sounds - although already more than 100 years old - contemporarily young and fancy as well as old-fashioned coming along with a musty and antiquated taste. On the one hand, many schools offering alternative concepts to public schools are labeled with Montessori or Waldorf ${ }^{2}$, promoting their institutions offensively as the modern choice of advanced education. Similarly, for practitioners of progressive education, it seems to be an unlimited source of innovation, providing proven and recommended actions and hundreds of practical ideas for everyday teaching and training life. On the other hand, a large number of objections have frequently been made since the very beginning accusing these schools and their founding concepts either to be nothing more than just a marketing and money-makingmachine without any specific quality, or their principles are denounced as being backward, irrational, mythologically overloaded or politically retarded. ${ }^{3}$ Against this background, it seems worth to prove how helpful the slogan 'From the perspective of children' is in today's educational debate ${ }^{4}$.

To answer the question how and where pedagogical thoughts have to start from the perspective of children, in their critical meta-analysis, the authors analyze the historical context where the slogan emerged first. After one hundred years of educational thinking and reflection, standard counter-arguments against this view can be clustered in order to elaborate its particular pedagogical meaning and to eliminate ideological prejudices and argumentative dead ends. We finally present the hypothesis that a clear distinction is necessary to separate 
the use of the phrase as a "slogan" from its use as a "working formula". In our view, a nondifferentiated use of language is identical with a mix-up in theoretical reflections. Therefore, we insist on a precise and limited use of the plural 'From the perspective of children'. The latter is going to be elucidated as a re-interpretation from the standpoint of educational interaction and from the inter-generational perspective. ${ }^{5}$

\section{From the Perspective of the Child - A Progressive Slogan and its History}

It was not until the end of the 19th century that thinking about education from the standpoint of children became part of a massive pedagogical and social movement. In contrast to "a world bristling with weapons, a world in which for the opening century there was not an inch of free ground to set one's foot upon” (Key, 1909,p. 1), the Swedish writer Ellen Key elaborated her paradigmatic 'Century of the Child' at the millennium of the 20th century. Soon after publishing it, she was emphatically celebrated by reviewers and journalists from all over the world. Several editions and translations followed in a few years' time. Along with other representatives of progressive educational approaches, the proclamation of a tensionfree reunification of "the child" and "the community" (Oelkers, 1988, p. 208) was regarded as the elementary step towards the realization of a harmonic life world based on the trinity of nature, development, and individuality (Baumgart, 2001, pp. 121 - 122). The rise of the new millennium was expected to be a jump-start for the world in harmony with itself. The spirit of departure towards something "really new" was in the air. In every child, the hope or at least the possibility for a fundamental change was reborn. With doubtful reference to Rousseau ${ }^{6}$, images of the holy nature were boosted normatively in contrast to civil alienation.

The formula 'From the perspective of the child' was the educational spirit of the age and itself connected to a long tradition of educational ideas from Comenius and the era of Enlightenment to the present insisting on the personality of every child in contrast to contentand teacher-driven concepts where the child is just an empty box to be filled or clay to be formed in passivity. Progressive approaches argued emphatically against concepts where learning means to oppress liberty and creativity by stupid drill and obedience to authority as an adaption to the existing order (Dietrich, 1963).

Turning the adult-driven principles upside down, the "holy child" appeared as "the constructor of mankind" as "the master-teacher" and the "leader" whom parents, not only have to understand but to follow! Ellen Key asked representatively what would happen if we, the adults, finally succeeded with the insight that: 
... the great secret of education lies hidden in the maxim, 'do not educate'? Not leaving the child in peace is the greatest evil of present-day methods of training children.

Education is determined to create a beautiful world externally and internally in which the child can grow. To let him move about freely in this world until he comes into contact with the permanent boundaries of another's right will be the end of the education of the future. Only then will adults really obtain a deep insight into the souls of children, now an almost inaccessible kingdom. (Key, 1909, pp. 109-110)

The anthropology of the child (Montessori, 1913) was not only a foundation of education but it turned into its major objective to be realized through careful observation, and what they called “negative education” in reference to Rousseau’s Emile (Rousseau, 2007). Allowing the natural development of the child according to its immanent course and preventing it from the harmful influence of civilization was all an educator should do. Following the ideal of a gardener, parents, teachers and caretakers, one needs patience and a strong belief in the laws of Mother Nature to succeed in educational attempts. Good and evil are clearly allocated. The nature of the child is no longer only different from the one of adults but is regarded as superior, better, pure, advanced and more amiable.“The adult has not contaminated his child when he allowed him to follow his course of life, but when he prevented him and pushed him aside from the natural development into digressiveness” (Montessori 1980, p. 233) ${ }^{7}$.

An elusive and ideological driven seeking for simplicity, clarity, unambiguousness and security was satisfied in times of apocalyptic sentiment. This might be one of the main reasons why alternative approaches are still popular today in our risky (post-) modern times of pluralism, complexity, diversity, flexibility and fragility. But, from a very German retroperspective, the apolitical, community and companionship-oriented approaches of progressive education in the early 20th century and their specific jargon started a fatal liaison with those socio-political movements which directly and indirectly supported the National Socialistic body of thought. Those, who celebrated collectivity and unity as an end in itself by self-immunization from critics, became blind towards totalitarian infiltrations and massmanipulation (Adorno, 1998, pp. 191-204). Politically, the concepts of "progressive education" were either uninterested respectively disregardful or bound to a naive version of a strong belief in a national community as the ultimate goal of natural development. ${ }^{8}$ Fatally enough, this stand-point of human Darwinism was in accordance with what the Nazis’ propaganda was commanding in death-bringing consequence for millions, who did not Journal of Education and Research, August 2013, Vol. 3, No. 2 
belong to the Aryan race. Unmasking these naturalistic, romantic and dogmatic traits and their dialectics in various alternative concepts is part of the critical task to be fulfilled by educationists today. Whoever uses the slogan 'From the perspective of the child' should be aware of this collective blind spot.

Besides these lessons, we have to learn from history, even from the individual perspective, we have several critical remarks regarding the connectivity of "progressive approaches” in today's educational debates. Whenever an author writes about the perspective of the child, the question must arise which child he is thinking of. Is it a boy or a girl, living in a city or a village, today or 50 years before, in Nepal, Germany or Italy? Was s/he born of rich parents, or poor ones, a single child or has brothers and sisters? If yes, how many? Are both parents still alive and are they interested in education? Or does this not make any difference? In consideration of the diversity of possible life-worlds of children, speaking about the child sounds presumptuous and megalomaniacal. Therefore, we strongly recommend the usage of the plural instead of the mainly in singular used anthropological terms of progressive educational concepts. ${ }^{9}$ The latter is tending towards essentialism suggesting misleadingly that the character and nature of any child is similar - and above all fully understandable in case you collect the right data, read the right books and have the right belief. It sounds paradoxical, but following the progressive path consistently, in the end, a stereo-typed sample child is shining with the natural glory of the salvation of mankind in surprising ignorance of the individuality of every child alive. The theoretical foundation is in vast contradiction to its own practical guidelines.

Therefore, any educational theory from the perspective of the child in singular is, in our view, an empty phrase with no value as an educational maxim. Anyhow, this does not affect the open plural term 'From the perspective of children', which is still a necessary and useful working formula. In the following analysis, we draw a distinction between (a) the perspective of educational interaction between adults and children, and (b) its status as the basic foundation of the inter-generational relation with a special focus on Bildung ${ }^{10}$ and selfcultivation. This slight difference has most serious consequences moving the spotlight from the analysis of the practical field of educational applications and individual settings to the founding side of a general perspective focusing the relation between the older and the younger generation and its ethical implications on pedagogical thinking.

Journal of Education and Research, August 2013, Vol. 3, No. 2 


\section{From the Perspective of Children - Educational Interaction}

It is self-explainable, anyhow worth to mention, that theories about childhood are not expounded by children themselves but always from adults. Similarly, the intentional action of education is a paradoxical one, as it requests children to deal with selected cultural objects and offers but with 'inner drive' in self-directed autonomy. This does not mean that children are able to do so without any help of culturally experienced adults who support the worldbeginners from time to time and prepare the learning-platform adequately according to the children's age or capability. The ability of self-activation of children is not the solution to educational problems, but its natural foundation. In the words of Immanuel Kant:

Man needs nurture and culture. Culture includes discipline and instruction. These, as far as we know, no animal needs, for none of them learn anything from their elders, except, birds, who are taught by them to sing [...] Man can only become man by education. He is merely what education makes of him. It is noticeable that man is only educated by man that is, by men who have themselves been educated. (Kant, 2003, pp. 5 -6)

Therefore, with a modern twist, intentional education is always a mode of demonstration by adults (Prange, 2005) that aims at making something comprehendible for children. In this way, the objective is not to detect the eternal nature of the child once and forever in order to define the ultimate educational rules for educators, but to keep in mind that our educational behavior in our present context is part of a historical and cultural self-image of childhood which evolved over time. Ariès (1962) describes vividly that this image is far away from being consistent and immutable over the years but a product of its time and its Zeitgeist starting with the revival of childhood only some 400 years ago at the threshold of the era of industrialization. Ariès (1962) further illustrates:

In the Middle Ages, at the beginning of modern times, and for a long time after that in the lower classes, children were mixed with adults as soon as they were considered capable of doing without their mothers or nannies, not long after a tardy weaning (in other words, at about the age of seven). They immediately went straight into the great community of men, sharing the work and play of their companions, old and young alike. The movement of collective life carried along in a single torrent all ages and classes, leaving nobody any time for solitude and privacy. [...] Medieval civilization had forgotten the paideia of the 
ancients and knew nothing as yet of modern education. That is the main point: it had no idea of education. (p. 411)

The re-invention of childhood in the 19th century came along with the establishment of the public educational sector with kindergartens, schools and colleges on the one, and families as the private institution of education on the other side. In different ways, this changed social reality as the common understanding of a particular concept of childhood is now highly influencing the setting of educational interaction between adults and children in today's world.

Looking one-sided at this changing explicitly from the perspective of children prevents us from an adult-limited focus on educational thinking and action. With the help of Georg Herbert Mead's approach of Symbolic Interactionism, we are able to analyze and differentiate the motives and behaviors of social actors without the need for hierarchy or superiority. Here, children and adults are in an equal way part of social reality and determine each other with reciprocal influence on various levels.

Every person lives in a world of social encounters, involving him either in face-to face or mediated contact, he tends to act out what is called a line - that is, a pattern of verbal and nonverbal acts by which he expresses his view of the situation and through this his evaluation of the participants, especially himself. Regardless of whether a person intends to take a line, he will find that he has done so in effect. The other participants will assume that he has more or less willfully taken a stand, so that if he is to deal with their response to him, he must take into consideration the impression they have possibly formed of him. (Mead, 1967, p. 5)

This understanding is fundamentally breaking with both types of concepts we already discussed - with those that regard children as passive, care- and protection-needy immature creatures as well as it is straightening out a view on children which is over-estimating their capabilities by dealing with them like with “small adults”. If we view on educational interaction from the perspective of children, we take into consideration that they co-construct our image as a similar productive part of reality with likewise influence on what we call “childhood”. For a few years, contemporary studies on childhood have been interpreting this relation as a construct of cultural and inter-generational orders. Ethnography-based research on children's life-world is done as a qualitative inquiry in order to better understand their 


\section{8}

S. Gross and U. Wehner

specific way of perceiving the world, as comparable to the study of foreign peoples and cultures. These new approaches take children seriously and try to find methodological solutions to overcome the limitations of our own adult-based perspectives. No doubt, even this approach itself to view on educational interaction from the perspective of children is an intellectual creation of adults. We cannot avoid sticking to our own stand-point, although we try to manage it methodologically. What we can do is resolving the doubtful one-sided and mainly hierarchical-understood perspective of grown-ups through critical self-reflection and trying to find access to children's perceptions and their construction of educational orders. By this, the perspective of adults is no longer necessarily superior to the perspective of children but simply different. Educational attempts which act just following the doctrine to compensate lacking aspects detected by adults are missing their target group and are nothing more than a random set of trial-and-error actions. Any influence from educator's side is recognized by children only if it is applicable to their way of understanding, feeling, will and ability. Therefore, we have to understand first, how the world looks like through their eyes. Finally, questions open up regarding objectives, means and guiding principles for those, who are involved in the field of education. Here, our working formula 'From the perspective of children’ leads to specific distinctions while talking about pedagogics and its ethical consequences.

\section{From the Perspective of Children - Inter-generational Perspectives}

Our elaboration of consequences on the practical level illustrated how educational interaction looks different. If we are able to follow a consequent perspective-taking approach, the question occurs at the cultural level once more. How to justify educational interventions in general? How do parents argue for their actions or their failure to provide support and care to their children? One of the initial questions Friedrich Schleiermacher, one of the founding fathers of academic education, asked in his lectures in 1826 was "What does the elder generation want with the younger one?"11 (Schleiermacher, 2000, p. 9).As a child of his time and a typical representative of enlightened thought, for him, education was not yet delegated to formal institutions but an integrated part of social life. Important in our context is that Schleiermacher is neither asking what the elder generation wants from the younger one, nor is he asking only the opposite way round, what children may expect from their parents. His participatory approach to want something together with somebody does not neglect the generational differences, but takes them, in a modern re-interpretation, as the starting-point of

Journal of Education and Research, August 2013, Vol. 3, No. 2 
a permanent struggle for a common configuration of the future. If you want something with somebody, the preposition in our context has at least three relevant dimensions: In a temporal understanding, the process has to take place at the same time together with the children. From the modal perspective, it has to be conducted in a certain and specific way, which differs, e.g. from talks only among adults. The causal interpretation is focusing the perspective-taking in order to do this from the specific view children have towards the world.

Historically, Schleiermacher for the first time expressed the aspiration that education is not only a task for individuals but a trans-personal mission which addresses the whole generation of adults. Its specific form as the linking part between generations has consequences for both sides. If we look at it from the perspective of children, education is no longer a deficit-oriented approach focusing where children are not yet as competitive as adults. Instead, it has to be the genuine pedagogical interest of the elder generation to strengthen their capabilities and to regard "support" as the major function of any educational attempt. From children's perspective, the main question is how they can be enabled and assisted step by step to become finally full members of the society, able to participate entirely in the conservation and improvement of the existing life-world. This concept links educational thinking strongly with ethical reflections and politics and boosts them out of the private into the public sphere. It is not only a personal matter how parents deal with their children but also of public interest.

For the elder generation of adults, this demand includes the imposition of a permanent critical self-reflection with a serial of inconvenient questions: Why do we really want children? Which parts of our way of living do we want to be continued? To which aspects are we ready to say goodbye? How do we present and demonstrate our way of living according to children's capabilities and their level of understanding? How do we organize our educational settings with an inviting appearance which does not scare off children, as we need them for our co-operative educational enterprise? How do we ensure the sustainability of our lifestyle and culture?

Simple kindness or patiently waiting for any kind of natural development is not enough if you take these questions seriously. Therefore, the slogan 'From the perspective of the child' is simplistic and insufficient to cover the socio-cultural dimension of education. In contrast, the working formula 'From the perspective of children' is the repetitive reference-point for 
educational self-awareness and renovation within the adult generation. In explicit reference to Schleiermacher, the critical educationist Klaus Mollenhauer was asking once, if there do exist "fundamental elements in present pedagogical concepts, a minimum standard of problems which cannot be ignored by anyone who wants to educate in a responsible way no matter at which position of our educational system (s)he is involved” (Mollenhauer,1983, p. 16). While presentation and re-presentation are the tasks for educationists, their corresponding counterparts from the perspective of children are developmental preparedness as the fundamental conviction that children will learn and the ability of self-initialization of solving problems and self-given tasks (Mollenhauer, 1983). The intergenerational relation of adults and children is a temporary constellation appearing in a regular reprise where parents have limited time to equip children with those cultural goods and skills which are necessary to cope with the challenges of today's and tomorrow's world. What every elder generation wants is a maximum continuation of proven practices and a survival of their own achievements. From the very perspective of children, this debate cannot take place in exclusive conservative reference to the past but must contain a prospective view towards the future.

\section{Conclusion and Next Steps}

Thinking about education from the perspective of the child was a key-demand of progressive educational concepts. Although these approaches, as shown, entangle themselves in self-contradictions and insufficiency, the status of children remains a constitutive part of any pedagogical consideration. Anyhow, our historical reflections, considered from various sources, showed that this has to be realized in perspective-taking reflections both in theory and practice. This means, children should be represented practically or in an advocatory way in debates on the distribution of achievements of the welfare-state as well as their access to education should be relieved from the income-status of their parents. This argument includes

the ethical thesis that an advocatory practice should not only intend effects on the progression of maturity for the addressees, but also be thought-provoking for the producers of ethical reflections.

The follow-up of our critical reflection is going to be a qualitative empirical research on our hypothesis to investigate the differences in views on educational interaction from the perspectives of the elder and the younger generations. Educational phenomenon like punishment, teaching and learning, rights and duties, acting in conflicts or making decisions

Journal of Education and Research, August 2013, Vol. 3, No. 2 
seem to content an un-retrieved treasure to specify and cluster the variety of perspectives and to relate them to their cultural contexts. In the long run, the detection of differences will be the preliminary stage for constructing bridges and minimizing gaps between the generations.

\section{Notes}

${ }^{1}$ According to Boehm, at least for Germany the end of the progressive movement is clearly marked with the takeover of the National Socialists in 1933, while debates are still ongoing regarding its beginning. 1880, 1890, 1895 or 1900 are key-dates, depending on the incident, one regards as the initial cause (Boehm, 2012, pp. 10-12).

${ }^{2}$ Rudolf Steiner founded his first school in 1919 to serve the children of factory workers at the Waldorf-Astoria cigarette factory in Stuttgart. To which extent these schools are following the pedagogical concepts of their famous name-givers today is another topic worth to be examined.

${ }^{3} \mathrm{~A}$ kind of renaissance of this strongly polarized debate can be observed from time to time within the scientific community (compare, Boehm, 2012; Dietrich, 1963; Oelkers, 1988; Wehner, 2009).

${ }^{4}$ The current discourses in the Western world are not revolving around totally new topics but cover periodically classics like, 'Economisation of education and its consequences', 'Childtreatment according to the latest findings in brain-research', 'Science for kindergartenchildren', 'To whom belong our children? - parental rights vs. governmental law', 'Fostering early linguistic language development', or 'Do we need more or less discipline and strictness in class-rooms?'

${ }^{5}$ The origins of an explicit intergenerational thought pattern in the field of education can be found for the first time in Friedrich Schleiermacher's Vorlesungen ueber Paedagogik from 1826 (Schleiermacher, 2000). In his historiographic research thesis Wehnerelaborated extensively how this idea shaped educational thinking as a trans-personal, social and cultural endeavour of public interest reflecting the whole history of mankind as the pendant to an individual perspective (Wehner, 2011, pp. 36 - 37).

${ }^{6}$ Regarding one-sided and limited interpretations of Rousseau's oeuvre, compare Gross (2008) and especially Grell (1996).

7 “Der Erwachsene hat sein Kind nicht verdorben, als er ihm nachgab, sondern als er es daran hinderte, sein Leben zu leben, und es dadurch aus der natuerlichen Entwicklung in die 
Abwegigkeit draengte” (Montessori, 1980, p. 233) translated by the authors and cited from Wehner (Wehner, 2009, p. 3).

${ }^{8}$ The relation of progressive educational approaches with the philosophy and propaganda of the Nazis is deeply analysed by Oelkers (1988).

${ }^{9}$ A brief look in Montessori’s Pedagogical Anthropology will approve this view (Montessori, 1913).

${ }^{10}$ The fine nuances of the term 'Bildung', which make the term untranslatable, are unique. Some say "It is no accident that it was the Germans who gave to the world this intellectually stimulating and very human literary form which we call the novel of personal cultivation and development. [...]The inwardness, the culture ['Bildung'] of a German implies introspectiveness; an individualistic cultural conscience; consideration for the careful tending, the shaping, deepening and perfecting of one’s own personality” (Bruford, 2009, p. vii).

11 “Was will denn eigentlich die aeltere Generation mit der juengeren?” (Schleiermacher, 2000, p. 9) translated and emphasized by the authors.

\section{References}

Adorno, T. W. (1998). Critical models: Interventions and catchwords (H. W. Pickford, Trans.). New York: Columbia University Press.

Adorno, T. W. (2003). Can one live after Auschwitz? A philosophical reader (R. Livingstone et al., Trans.). Stanford, C. A.: Stanford University Press.

Ariès, P. (1962). Centuries of childhood: A social history of family life (R. Baldick, Trans.). New York: Vintage.

Baumgart, F. (Ed.). (2001). Erziehungs- und Bildungstheorien: Erlaeuterungen, Texte, Arbeitsaufgaben. [Theories on education and Bildung: Explanations, writings, exercises]. Bad Heilbrunn: Klinkhardt.

Boehm, W. (2012). Die Reformpaedagogik. Montessori, Waldorf und andere Lehren [Progressive education. Montessori, Waldorf and other concepts]. Muenchen: C. H. Beck. Bruford, W. H. (2009). The German tradition of self-cultivation: "Bildung”from Humboldt to Thomas Mann. Cambridge, U. K.: Cambridge University Press.

Dietrich, T. (1963). Die paedagogische Bewegung vom Kinde aus [The pedagogical movement "From the perspective of children”]. Bad Heilbrunn: Klinkhardt.

Goffman, E. (1967). Interaction ritual: Essays on face-to-face behavior. New York: Anchor. Journal of Education and Research, August 2013, Vol. 3, No. 2 
Grell, F. (1996). Der Rousseau der Reformpaedagogen: Studien zur paedagogischen Rousseauinterpretation. [The Rousseau of progressive educationists: Studies on the pedagogical interpretation of Rousseau]. Wuerzburg: Ergon.

Gross, S. (2010). Inequality and emancipation: An educational approach. Journal of Education and Research, 2, 9 -16.

Gross, S. (2008). Child-centered learning and its lost trail: A critical review from Rousseau to the present. Kathmandu: NELTA Lalitpur Voice.

Kant, I. (2003). On education [A. Churton, Trans.]. Mineola: Dover.

Key, E. (1909). The century of the child. New York: Putnam. Retrieved from http://www.archive.org/details/centuryofchild00keyeuoft

Mollenhauer, K. (1983). Vergessene Zusammenhaenge:Ueber Kultur und Erziehung [Forgotten connections: On culture and education]. Weinheim: Juventa.

Montessori, M. (2002). The Montessori method. Mineola: Dover.

Montessori, M. (1913). Pedagogical anthropology [F. T. Cooper, Trans.]. New York: Frederick A. Stroke.

Morgan, E. (1994). The descent of the child: Human evolution from a new perspective. London: Souvenir.

Oelkers, J. (1988). Paedagogischer Liberalismus und nationale Gemeinschaft: Zur politischen Ambivalenz der "Reformpaedagogik” in Deutschland vor 1914 [Pedagogical liberalism and national community: The political ambivalence of "progressive education" in Germany before 1914]. In U. Hermann \& J. Oelkers (Eds.) (1988), Paedagogik und Nationalsozialismus, in Zeitschrift fuer Paedagogik. 22, Beiheft [Education and the Nationalsocialism. In Journal of Education, 22, Supplement].

Prange, K. (2005). Die Zeigestruktur der Erziehung: Grundriss der operativen Paedagogik [The demonstrative structure of education: Outline of operative pedagogics]. Paderborn, Muenchen, Wien and Zuerich: Ferdinand Schoeningh.

Rousseau, J. J. (1987). The basic political writings (D. A. Cress, Trans.). Indianapolis, Cambridge: Hackett. (Original work published between 1750 and 1762)

Rousseau, J. J. (2010). Emile, or, on education: Includes Emile and Sophie, or the solitaries (C. Kelly \& A. Bloom, Trans. \& Eds.). Hanover, New Hampshire: Dartmouth College Press. (Original work published 1762) 
14 S. Gross and U. Wehner

Schleiermacher, F. (2000). Texte zur Paedagogik: Kommentierte Studienausgabe Band 2, herausgegeben von Michael Winkler und Jens Brachmann [Writings on education: Annotated textbook] (M. Winkler \& J. Bachmann, Eds. \& Trans.). Frankfurt: Suhrkamp. Wehner, U. (2009). “Paedagogik vom Kinde aus": Versuch einer kinderphilosophischen Reinterpretation einer paedagogischen Formel ["From the perspective of children": A child-philosophical re-interpretation of a pedagogical formula]. Retrieved from www.widerstreit-sachunterricht.de/ebeneIII/wehner.pdf

Wehner, U. (2011). Generationelle Paedagogik: Die menschheitsgeschichtliche Seite von Bildung und das oeffentliche Moment von Erziehung [Generational pedagogics. The historical side of Bildung and the public aspect of education]. Paderborn, Muenchen, Wien and Zuerich: Ferdinand Schoeningh.

Journal of Education and Research, August 2013, Vol. 3, No. 2 